\title{
Doctrine of equivalents in Japan: criteria of special conditions and estoppel
}

First draft submitted: 29 March 2016; Accepted for publication: 30 March 2016; Published online: 18 April 2016

Keywords: claim $\bullet$ doctrine of equivalents $\bullet$ generic $\bullet$ innovator $\bullet$ Japan $\bullet$ literal interpretation $\bullet$ manufacture $\bullet$ patent infringement

- DKSH Japan KK, Iwaki Seiyaku Co Ltd, Takata Pharmaceutical Co Ltd, and POLA-Pharma, versus Chugai Pharmaceutical Co Ltd and The Trustees of Columbia University in the City of New York, decision by the Intellectual Property High Court of Japan (Heisei 27 [ne] 10014) dated 25 March 2016 [1].

- DKSH Japan KK, Iwaki Seiyaku Co Ltd, Takata Pharmaceutical Co Ltd, and POLA-Pharma, versus Chugai Pharmaceutical Co Ltd Grand Panel decision by the Intellectual Property High Court of Japan (Heisei 27 [gyo-ke] 10014) dated 25 March 2016 [2].

The Grand Panel of the Intellectual Property High Court of Japan (IPCH-J) accepted the argument made by Chugai (the patentee), a subsidiary of F Hoffmann-La Roche AG, that the four generic drug makers including DKSH Japan K.K. infringed their patent (Japanese patent no. 3310301) directed to a vitamin $\mathrm{D}$ derivative by applying the Doctrine of Equivalence (DoE). The pharmaceutical product in suit is a maxacalcitol formulation, and a patent covering the active ingredient has already expired in 2010, but the subject patent in suit still in force that covers a manufacture process thereof. The claims of the patent in suit recite the use of cis-type vitamin $\mathrm{D}$ structure as a starting material and an intermediate thereof, whereas the four generic drug makers have used the corresponding trans-type structure, and have argued that their act does not fall within the scope of the patented claims. However, Chugai argued that the difference in cis- and trans-structure is inessential to the invention and, thus, the manufacture process used by the four generic makers infringes the patent in suit by means of the DoE. The IPHC-J held that whether or not the DoE is applicable should be decided based on whether the accused product satisfies the patent elements, which constitutes the essential part of the invention, and if so the DoE shall be applied, and that even if there is any difference in the other parts, in other words, inessential parts, this does not negate the satisfaction of the claim elements. Furthermore, the IPCH-J analyzed the patent and stated that the patented invention contributed to the art by providing a novel manufacture route, particularly in terms of introducing side chains of maxacalcitol at the 20-alcohol position by a single step and, thus, the difference in isomerism, in other words, trans- or cis-structure, is not relevant to the essential part of the claims. In addition to inessential part, the first criteria of the five stipulated in the Japanese Supreme Court's precedent, the IPCH-J further gave judgments favorable to the patentee regarding the other criteria of the DoE including possibility of interchangeability, ease of interchangeability, nonprior art and special circumstances and estoppel. With respect to estoppel, the Court further
Takeshi S Komatani

Shusaku Yamamoto, 17th Floor, Grand Front Osaka Tower, C 3-1 Ofuka-cho, Kita-ku, Japan tskomatani@shupat.gr.jp

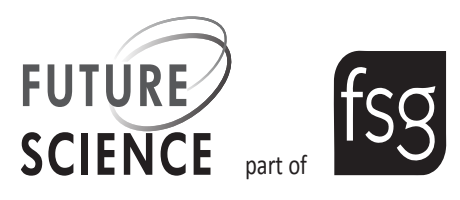


analyzed in detail and held that even if there were other embodiments different from but obvious from the literal interpretation of the claims, which is substantially the same as the claims, and the applicant could have arrived at that embodiments, that circumstances alone are not sufficient to recognize that there was a special circumstance and estoppel to negate the fulfillment of the DoE. Furthermore, in order to negate the fulfillment, it would be required to show the circumstances where the applicant/patentee has recognized the alternative embodiments that are outside the scope of the claims in an objective and external manner, for example, the applicant has described the particular alternative embodiments in the patent specification or in the published academic journal published around the time of filing of the patent, etc. In the subject case, the defendants (four generic drug makers) fail to show that the patent specification or any other published articles describe such an alternative, in other words, the transtype structure. The IPHC-J also held that the patent remains valid in the decision issued on the same date. The decision regarding the infringement was issued by the Grand Panel of IPCH-J, which is similar to en banc system in USA, where all the four departments are involved and the judgment are deemed to be the position of the entire IPHC-J.

\section{Disclaimer}

This update describes the opinions and observations of the author as a Japanese patent attorney and does not necessarily represent the viewpoints of the author's employers or author's firm. By its nature, the subject article provides the author's general opinion, and necessarily limited discussion of various topics; it does not purport to give specific legal advice or a substitute for legal counsel. As legal advice must be tailored to the specific circumstances of each case, nothing provided herein should be used as a substitute for advice of competent counsel. The author and the author's firm assume no liability for the use or interpretation of information contained herein. The author and the author's firm expressly disclaim all liability in respect of anything done or omitted to be done wholly or partly in reliance of this material.

\section{Financial \& competing interests disclosure}

The author has no relevant affiliations or financial involvement with any organization or entity with a financial interest in or financial conflict with the subject matter or materials discussed in the manuscript. This includes employment, consultancies, honoraria, stock ownership or options, expert testimony, grants or patents received or pending, or royalties.

No writing assistance was utilized in the production of this manuscript.

\section{References}

1 Courts in Japan (Japanese). http://www.courts.go.jp

2 Courts in Japan (Japanese). http://www.courts.go.jp 